\title{
Análise exploratória de simulações sociais computacionais por meio de estatística multivariada e Mapas Auto-Organizáveis
}

Exploratory analysis of computational social simulation outputs by multivariate statistics and selforganizing maps

M. A. S. da Silva*, A. V. Santos, M. H. G. Dompieri, S. dos S. Medeiros, M. R. M. de Almeida

Embrapa Tabuleiros Costeiros, 49025-040, Aracaju-Sergipe, Brasil

*marcos.santos-silva@embrapa.br

(Recebido em 29 de setembro de 2015; aceito em 04 de maio de 2016)

\begin{abstract}
Visando oferecer subsídios para a avaliação do Plano Territorial de Desenvolvimento Rural Sustentável do Ministério do Desenvolvimento Agrário este trabalho teve como objetivo a aplicação da análise de componentes principais, da análise de agrupamentos pelo método hierárquico aglomerativo e da rede neural do tipo Mapa Auto-Organizável de Kohonen na análise exploratória de resultados de simulações sociais computacionais do sistema socioterritorial "Território Rural Sul Sergipano". A metodologia basea-se na Sociologia da Ação Organizada e no método Soclab. As análises estatísticas mostraram que o sistema socioterritorial em questão tem estrutura simples e determinística, ou seja, apresenta um jogo social cooperativo com forte tendência à estabilidade mesmo com situações de interesses divergentes. A análise neural permitiu a caracterização das situações atípicas quando ocorrem a estabilidade do sistema social.
\end{abstract}

Palavras-chave: sistema socioterritorial, redes neurais artificiais, teoria social

In order to provide valuable information for the assessment of the Territorial Plan for Sustainable Rural Development of the Ministry of Agrarian Development this work aimed at the use of principal component analysis, cluster analysis by the agglomerative hierarchical method and the Self Organizing Map artificial neural network in the exploratory analysis of the results of computer simulations of the social socioterritorial system "Southern Rural Territory of Sergipe". The methodology has been based in the Sociology of Organized Action and Soclab framework. Statistical analyses showed that this socio-territorial system has a simple and deterministic structure, so, presents a cooperative social game with a strong tendency to reach a steady state even in situations of conflicting interests. The neural analysis allowed the characterization of atypical situations when the stability of the social system occurs.

Keywords: socioterritorial system, artificial neural network, social theory

\section{INTRODUÇÃO}

A ciência social computacional procura aproximar as ciências sociais, no sentido amplo, das ciências computacionais por meio do estudo interdisciplinar de fenômenos sociais a partir do uso combinado de técnicas oriundas das duas ciências [1]. Um dos seus objetivos é a compreensão das relações e interações entre diversos atores sociais, que são consideravelmente complexas para serem compreendidas por métodos analíticos [2-4]. De fato, a explosão combinatória de todas as possibilidades de comunicação, interação, troca de informação e tomada de decisão num sistema social impede ou torna difícil a explicação do fenômeno pela simples análise dos seus componentes sem considerar as diversas possibilidades de interação entre elas [5]. Essa nova ciência aborda, de diferentes formas, tanto aspectos estruturais quanto comportamentais, sejam eles individuais ou coletivos.

A modelagem e a simulação computacional tem usado diferentes ferramentas para análise dos fenômenos sociais, com destaque para os sistemas multi-agentes, para a análise de redes sociais e para os métodos oriundos da ciência da complexidade. As abordagens vão desde trabalhos eminentemente empíricos até modelos baseados em teorias psicossociais ou sociais. Quando se considera trabalhos que se apoiam em teorias sociais destacam-se Joseph, Carley e Hong (2013) [6] sobre o Blau space; Silva, Marietto e Ribeiro (2008) [7] e Dittrich, Kron e Banzhaf (2003) [8] 
sobre a teoria dos Sistemas Sociais de Luhmann (1995) [9]; e Sibertin-Blanc et al. (2013) [10] que aborda a Sociologia da Ação Organizada [11,12].

A Sociologia da Ação Organizada (SAO) surgiu do estudo empírico das relações sociais em organizações formais nos anos 60-70, mas evoluiu para uma tese que generaliza o comportamento da ação coletiva estratégica. Segundo a SAO, toda organização formal e bem normatizada (empresas), formal com pouca normatização (conselhos, comitês e colegiados deliberativos) ou informal (grupo de amigos) será composta de atores sociais que criam um sistema social coeso e estável de interdependência. Essa coesão se dá pelas conexões ou relações entre os atores sociais que compartilham e controlam recursos materiais (e.g., financeiro) e imateriais (e.g., poder de influência). Estudar os sistemas sociais à luz da SAO significa analisar as relações de poder e interdependência entre os atores sociais que levam o sistema à estabilidade.

$\mathrm{O}$ estudo das relações sociais é de extrema importância quando consideramos as políticas atuais de desenvolvimento territorial, como o Programa de Desenvolvimento Territorial Rural Sustentável do Ministério do Desenvolvimento Agrário. O MDA (2005a, p.28, grifo nosso) [13] define o território como:

... um espaço físico, geograficamente definido, geralmente contínuo, compreendendo cidades e campos, caracterizado por critérios multidimensionais, tais como o ambiente, a economia, a sociedade, a cultura, a política e as instituições, e uma população, com grupos sociais relativamente distintos, que se relacionam interna e externamente por meio de processos específicos, onde se pode distinguir um ou mais elementos que indicam identidade e coesão social, cultural e territorial.

A definição acima evidencia que o foco do MDA são as relações e processos sociais, e que o território é mais que uma paisagem ou espaço geográfico, ou seja, é o resultado de interações complexas entre o sistema social e o sistema espacial. Outro aspecto da política territorial do MDA é a concertação dos atores sociais em torno de um projeto comum, no caso, o desenvolvimento sustentável do território. A estratégia de ação do MDA estabelece que o principal objetivo dessa política pública é animar a formação ou consolidação das redes sociais por meio da criação de um mecanismo democrático de governança, que facilite, em última análise, a tomada de decisão coletiva via o equilíbrio de forças no jogo social $[13,14]$.

Segundo Silva et al. (2014) [15] e Furtado, Sakowski e Tóvoli (2015) [20], os Territórios Rurais do MDA podem ser analisados como organizações não fortemente estruturadas, cujo objetivo principal é decidir coletivamente sobre ações estratégicas para o desenvolvimento sustentável do território. Assim, estas organizações podem ser estudadas a partir da Sociologia da Ação Organizada, sendo que essa análise deve ser engendrada a partir de uma definição mais concisa e abrangente em torno do conceito de território. Ainda segundo os autores, compreender o território significa, primeiramente, admití-lo como um fenômeno social complexo que pode ser analisado a partir da abordagem sistêmica. Segundo Moine (2006, 2007) [17, 18], o território é um sistema complexo evolutivo que associa um conjunto de atores de um lado, e o espaço geográfico que esses atores utilizam, modificam e gerem do outro lado.

Assim, a partir da abordagem sistêmica e da análise social territorial segundo o método Soclab [10], amparado na Sociologia da Ação Organizada, Silva, Sibertin-Blanc e Gaudou (2011) [19], Silva et al. (2014) [15] , Silva (2014)[16] e Furtado, Sakowski e Tóvoli (2015) [20] modelaram o sistema socioterritorial do "Território Rural Sul Sergipano". Esses trabalhos mapearam as relações de poder no Território e realizaram a modelagem e simulação sociais para se avaliar em quais situações o sistema se torna estável. Apesar das limitações inerentes a qualquer processo de modelagem, Silva (2014) e Furtado, Sakowski e Tóvoli (2015) [15,20] mostraram que a modelagem e simulação social auxilia a compreensão do sistema socioterritorial, assim como, permite criar uma linguagem padrão de comunicação de estudos sociológicos sobre a análise das interdependências sociais.

Cada simulação social, a partir do método Soclab, gera um conjunto de resultados que podem ser analisados individualmente ou em conjunto, quando se considera várias simulações. VillaVialaneix, Sibertin-Blanc e Roggero (2014) [21] analisaram estatisticamente e a partir da rede neural Mapa Auto-Organizável de Kohonen (conhecido com rede neural artificial SOM, do inglês 
Self-Organizing Maps) os resultados gerados a partir da modelagem e simulação do sistema socioterritorial responsável pela gestão da bacia do rio Touch, no sudoeste da França. Os autores mostraram que a análise estatística dos resultados das simulações sociais auxilia no processo de classificação das situações prováveis de estabilidade do sistema. Os dados de saída do modelo do sistema socioterritorial da bacia do rio Touch foram analisados por meio de duas redes SOM bidimensionais $(4 \times 4)$ com grade retangular para visualização dos resultados via hitmaps e para análise de agrupamentos, considerando que cada neurônio representa um grupo [22]. Os autores concluíram que a rede neural chegou a resultados similares aos das análises estatísticas, com a vantagem de oferecer melhores mecanismos de visualização dos dados. No entanto, a capacidade de visualização dos dados via planos de componentes [22-25], gerados a partir da rede SOM, não foi explorada.

No intuito de oferecer subsídios para a avaliação do Plano Territorial de Desenvolvimento Rural Sustentável (PDTRS) do Ministério do Desenvolvimento Agrário (MDA), o presente trabalho realizou uma análise exploratória dos dados de saída das simulações do sistema socioterritorial "Território Rural Sul Sergipano" (TRSS) [26, 27] por meio de métodos estatísticos e do Mapa Auto-Organizável de Kohonen, neste último caso, utilizando planos de componentes. Na seção 2 serão descritos o método de modelagem e simulação social Soclab, o estudo de caso e os principais resultados da simulação do sistema socioterritorial TRSS, a transformação dos dados, as técnicas estatísticas de análise descritiva e os Mapas Auto-Organizáveis. A seção 3 está dedicada aos resultados e discussões, e por fim, a seção 4 às conclusões.

\section{MATERIAL E MÉTODOS}

A pesquisa teve como ponto de partida os resultados gerados pela simulação do sistema socioterritorial "Território Rural Sul Sergipano" a partir do método Soclab [10, 20]. Os dados foram agrupados e transformados para aplicação de técnicas de análise exploratória estatística e computacional, nesse último caso, por meio da rede neural do tipo Mapa Auto-Organizável de Kohonen.

É importante destacar que há dois processos de modelagem do sistema socioterritorial. A modelagem social a partir da Sociologia da Ação organizada [15] e a modelagem computacional orientada a objetos a partir do método Soclab $[15,16]$. A simulação social é um terceiro processo realizado a partir da modelagem social computacional.

\subsection{O método Soclab}

O método Soclab formaliza e implementa em computador aspectos relevantes da Sociologia da Ação Organizada (SAO) $[11,12]$. A SAO define a ação coletiva organizada como um sistema político constituído de relações de interdependência entre atores sociais e tem como princípios [10]: 1) o sistema social é um constructo social, produzido pelos atores sociais. Ou seja, é autodeterminado, independente do ambiente externo e integra regras informais e formais; 2) o ator social sempre terá uma margem de manobra para atingir os seus próprios objetivos; 3 ) as estratégias do ator social são caracterizadas pela mobilização de recursos para exercer alguma forma de influência sobre os demais para atingir os próprios objetivos, que nem sempre estão consonantes com os do grupo; 4) supõe-se um mínimo de ordem coletiva, que é estabelecida pelas diversas interdependências entre as relações de poder e dependência.

Um conceito fundamental da SAO é o de zona de incerteza. Estas podem ser analisadas como sendo recursos controlados por um ator social e necessário por outros, como, por exemplo, um conhecimento técnico específico, a ascendência moral de um indivíduo sobre um determinado grupo, a capacidade de punir etc. Considerando que nesse jogo social não há submissão absoluta de nenhum ator social, tem-se que, por mais frágil que seja, cada ator social disporá de pelo menos um elemento de persuasão, zona de incerteza, que o mesmo explorará no momento de definição de suas estratégias. São essas zonas de incerteza que estruturam as relações de poder que podem se cristalizar ao longo do tempo. 
Segundo a SAO, qualquer sistema social, em que haja metas e objetivos coletivos, pode ser estudado a partir da análise da interdependência entre os atores sociais, que têm como elementos de conexão as zonas de incerteza. Silva et al. (2014) [15] e Furtado, Sakowski e Tóvoli (2015) [20] mostraram que os Territórios Rurais podem ser analisados como sistemas sociais, ou sistemas socioterritoriais, cujo objetivo comum é o desenvolvimento sustentável territorial. As principais dinâmicas sociais na SAO são engendradas por meio das relações de controle e dependência das zonas de incerteza, por parte dos atores sociais.

Para ilustrar, tomemos como exemplo a interdependência entre dois atores sociais hipotéticos [20]. Digamos que um determinado ator social (produtor rural) controla uma determinada zona de incerteza (acesso à propriedade rural). O produtor pode facilitar o acesso à propriedade ou não a outro ator social (agente ambiental). Este por sua vez precisa ter acesso à propriedade para elaborar os seus relatórios de conformidade ambiental (zona de incerteza) necessários para que o produtor rural obtenha acesso a financiamentos. No entanto, se o produtor rural liberar totalmente o acesso ao estabelecimento rural poderá se comprometer junto às instâncias de fiscalização ambiental e, se o agente ambiental extrapolar em sua capacidade de fiscalização poderá intimidar o produtor rural, que por sua vez poderá dificultar o acesso à propriedade. Neste sistema socioterritorial hipotético, os dois atores sociais devem entrar num acordo para que nenhuma das partes seja prejudicada e que haja perenidade nas relações.

Sibertin-Blanc et al. (2013) [10] formalizaram a SAO de forma a tornar possível a modelagem e a simulação computacionais de sistemas sociais. A Figura 1 mostra o metamodelo proposto pelos autores, em que são apresentadas as duas principais entidades: ator social e recurso, e as duas entidades de ligação entre elas, controla e depende. Pode-se resumir o modelo da forma que segue: o ator social $a_{n}$ é dotado de atributos como capacidade de ação $C_{n}$ (Eq. 1) e poder $P_{n}$ (Eq. 2), podendo agir segundo critérios próprios. A ação do ator social corresponde a alteração do estado $\lambda_{m}$, ou nível de acesso, do recurso $r_{m}$ que ele controla $\left(a_{\mathrm{n}} \rightarrow r_{\mathrm{m}}\right)$. Cada ator social controla pelo menos um recurso e depende $\left(a_{\mathrm{n}} \leftarrow r_{\mathrm{m}}\right)$ de um ou mais recursos, sendo $R$ o conjunto dos recursos. Para cada relação de controle ou dependência entre um ator social e um recurso deverá ser atribuído um ativo $s_{m n}$, ou peso, pelo ator social. Esse valor representa o quanto aquela relação é importante para o ator social. O impacto $I_{m n}$ (Eq. 3) da relação sobre o ator social deverá ser definida pela função de efeito $e_{m n}$ que, de fato, modelará matematicamente o impacto da relação sobre o ator social em função do nível de acesso ao recurso (estado do recurso). Os autores El Gemayel (2013) [28], Sibertin-Blanc et al. (2013) [10], Silva et al. (2014) [15], Silva (2014) [16] e Furtado, Sakowski e Tóvoli (2015) [20] descrevem o método Soclab com detalhes.

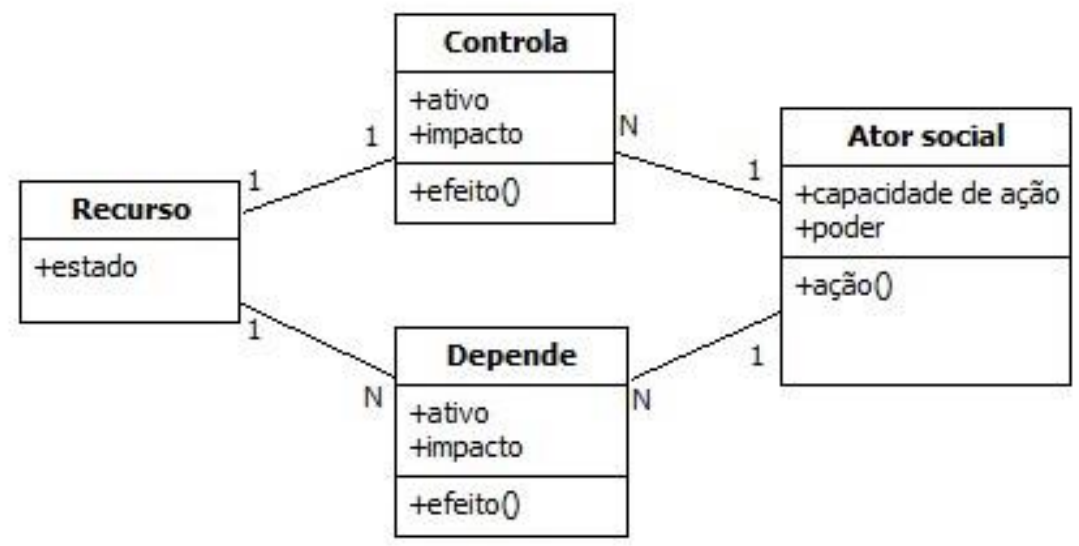

Figura 1: Metamodelo da SAO. Fonte: adaptado de Furtado, Sakowski e Tóvoli (2015)[20]. Elaborada pelos autores.

As funções de efeito $e_{m n}$ são contínuas, possuem domínio e imagem no intervalo [-10,10] e suas curvas podem assumir qualquer formato. Os estados dos recursos $\lambda_{m}$ podem assumir valores 
também no intervalo $[-10,10]$, sendo que valores negativos denotam dificuldade de acesso e valores positivos denotam facilidade de acesso. Cada ator social terá dez unidades de ativos $s_{m n}$ a serem distribuídos entre os recursos que mantém relações de controle ou dependência. O impacto do recurso $r_{m}$ sobre o ator social $a_{n}$ é o produto entre o valor da função de efeito $e_{m n}$ para essa relação e o ativo $s_{m n}$ atribuído a esta relação, considerando o estado do recurso $\lambda_{m}$ (Eq. 3). A capacidade de ação $C_{n}$ de um ator social $a_{n}$ é o somatório dos impactos das relações que ele depende $\left(a_{n} \leftarrow r_{m}\right)$ (Eq. 1$)$ e o poder $P_{n}$ o somatório dos impactos das relações que ele controla $\left(a_{n}\right.$ $\left.\rightarrow r_{m}\right)$ (Eq. 2).

$$
\begin{array}{cl}
C_{n}=\sum_{\left(\forall r_{m} \in R \mid a_{n} \leftarrow r_{m}\right)} I_{m n} & \text { Eq. } 1 \\
P_{n}=\sum_{\left(\forall r_{m} \in R \mid a_{n} \rightarrow r_{m}\right)} I_{m n} & \text { Eq. } 2 \\
I_{m n}=e_{m n}\left(\lambda_{m}\right) s_{m n} & \text { Eq. } 3
\end{array}
$$

Uma vez indentificados os atores sociais, os recursos, as relações, os ativos e as funções de efeito, resta definir o jogo social. No método Soclab, o jogo social pode ser dividido em três fases: 1) percepção, quando os atores sociais observam os estados dos recursos das relações que participa; 2) decisão, onde os atores sociais decidem qual ação tomar, ou seja, como alterará ou não os valores dos estados dos recursos que controla; e ação, quando o ator social age, alterando o valor do recurso que controla. O algoritmo assume que o ator social tem um comportamento racional limitado conforme Simon (1955) [29] e que o mesmo aprenderá por reforço positivo. Detalhes do algoritmo podem ser vistos em Furtado, Sakowski e Tóvoli (2015) [20] e El Gemayel (2013) [28].

A cada passo do algoritmo de simulação social, os estados dos recursos são alterados e a capacidade de ação e poder são recalculados para cada ator social. O algoritmo pára caso atinja o número limite de passos ou quando converge para a estabilidade do sistema social, ou seja, quando não houver mais interesse de cada ator social em agir (alterar o valor do estado dos recursos que controla). De fato, cada ator social procura maximizar a sua capacidade de ação e poder diante das condições impostas pelos demais atores. O jogo social é, portanto, dinâmico, sequencial e cooperativo ou não-cooperativo a depender da estrutura modelada da realidade do sistema socioterritorial.

\subsection{Estudo de caso: o sistema socioterritorial "Território Rural Sul Sergipano"}

O Território Rural Sul Sergipano (TRSS) foi criado em 2007 pela Secretaria de Desenvolvimento Territorial do Ministério do Desenvolvimento Agrário e compreende, atualmente, doze municípios: Arauá, Boquim, Cristinápolis, Estância, Indiaroba, Itabaianinha, Itaporanga d'Ajuda, Pedrinhas, Salgado, Santa Luzia do Itanhy, Tomar do Geru e Umbaúba. Sua população de 278.955 habitantes está distribuída em $3.950,90 \mathrm{~km}^{2}$, sendo que $44 \%$ residem em áreas rurais. O TRSS possui 1.256 famílias assentadas e 20.599 estabelecimentos da agricultura familiar. As principais atividades econômicas da região são a agricultura, com uma forte presença das culturas permanentes da laranja e do coco, e pecuária [33]. Ambas as atividades tem uma significativa participação da agricultura familiar. O TRSS é gerenciado por um colegiado composto, em 2010, por três representantes da sociedade civil e três do poder público, para cada um dos doze municípios. O colegiado territorial está subordinado ao Comitê Estadual dos Territórios, que por sua vez está ligado ao Conselho Nacional de Desenvolvimento Rural Sustentável e Solidário (Condraf).

Silva et al. (2014) [15] modelaram as relações de interdependência entre os principais atores sociais do TRSS tendo o colegiado territorial como ponto de partida. O estudo identificou os principais atores sociais (Tabela 1) e os principais recursos compartilhados pelos mesmos (Tabela 2). Os autores concluíram que: a) as relações entre as associações comunitárias e de produtores 
são mais intensas com a Emdagro, Pronese e prefeituras; b) as entidades ligadas à conservação ambiental apresentaram baixo grau de comunicação e interação com o TRSS; c) a pesquisa, por amostragem, em 65 associações comunitárias e de produtores da agricultura familiar mostrou que é baixo o nível de participação ou de engajamento das mesmas com o colegiado territorial; d) alguns atores sociais importantes para o processo de desenvolvimento sustentável do território mostraram baixa intensidade de cooperação ou comunicação com os demais atores sociais; e) há um certo conflito entre as políticas municipais e as estaduais; f) os atores sociais, apesar de divergências, têm expectativa de um jogo social cooperativo; e g) o sistema socioterritorial TRSS é de certa forma estável, apesar das fragilidades. A coerência e pertinência dos resultados da modelagem e da simulação foram validados por pesquisadores que desenvolvem trabalhos no TRSS.

A Tabela 1 mostra os valores médios para a capacidade de ação $\bar{C}_{n}$ de cada ator social após a convergência do algoritmo, assim como o desvio padrão $\delta\left(C_{n}\right)$ para a mesma variável e o poder médio $\bar{P}_{n}$. Os atores sociais com maior capacidade de ação são o Banco e a Pronese. De fato, em 2010 havia perfeita sintonia entre os agentes responsáveis pelos projetos de financiamento (Pronese) e os financiadores (Banco). Os atores sociais com maior poder são as associações comunitárias e de produtores da agricultura familiar (Asscomprod), controlador do recurso "espaço rural"; a Emdagro, controladora dos recursos "assistência técnica e extensão rural" e "difusão de tecnologia"; e o Sindicato controlador do recursos "mobilização sociopolítica". Maior poder de um ator significa que os demais atores sociais dependem fortemente dos recursos controlados pelo mesmo.

Tabela 1: Atores sociais com os rótulos das suas capacidades de ação CoAn, valores médios e desvios para a Capacidade de Ação, e o poder de cada ator considerando as simulações que convergiram para a estabilidade do sistema social.

\begin{tabular}{c|c|l|c|c|c}
\hline Ator social & $\begin{array}{c}\text { Recursos } \\
\text { que } \\
\text { controla }\end{array}$ & \multicolumn{1}{|c|}{ Descrição do ator social } & $\bar{C}_{n}$ & $\begin{array}{c}\delta \\
\left(C_{n}\right)\end{array}$ & $\bar{P}_{n}$ \\
\hline $\begin{array}{c}\text { Pronese } \\
\text { (CoA1) }\end{array}$ & R1 & $\begin{array}{l}\text { Empresa de Desenvolvimento } \\
\text { Sustentável do Estado de Sergipe }\end{array}$ & 49,30 & 6,00 & 29,5 \\
\hline $\begin{array}{c}\text { Emdagro } \\
\text { (CoA2) }\end{array}$ & R2 e R3 & $\begin{array}{l}\text { Empresa de Desenvolvimento } \\
\text { Agropecuário de Sergipe. }\end{array}$ & 20,62 & 6,19 & 67,4 \\
\hline $\begin{array}{c}\text { Asscomprod } \\
\text { (CoA3) }\end{array}$ & R4 & $\begin{array}{l}\text { Associações comunitárias ou de } \\
\text { produtores agrícolas familiares. }\end{array}$ & 35,86 & 5,74 & 92,6 \\
\hline $\begin{array}{c}\text { Banco } \\
\text { (CoA4) }\end{array}$ & R5 & $\begin{array}{l}\text { O Banco do Nordeste, o Banco Mundial e } \\
\text { o Banco do Brasil financiam projetos de } \\
\text { desenvolvimento local sustentável e de } \\
\text { baixo custo. }\end{array}$ & 55,09 & 3,40 & 29,1 \\
\hline $\begin{array}{c}\text { ConselhosMun } \\
\text { (CoA5) }\end{array}$ & R6 & $\begin{array}{l}\text { Conselho Econômico para o } \\
\text { Desenvolvimento Municipal / Conselho } \\
\text { Municipal para o Desenvolvimento } \\
\text { Sustentável. }\end{array}$ & 19,52 & 6,45 & 6,7 \\
\hline $\begin{array}{c}\text { Prefeitura } \\
\text { (CoA6) }\end{array}$ & R7 & Administração municipal & 32,12 & 5,00 & 5,7 \\
\hline $\begin{array}{c}\text { Sindicato } \\
\text { (CoA7) }\end{array}$ & R8 & Sindicato dos trabalhadores rurais & 16,70 & 7,22 & 58,0 \\
\hline $\begin{array}{c}\text { Embrapa } \\
\text { (CoA8) }\end{array}$ & R9 & $\begin{array}{l}\text { Empresa Brasileira de Pesquisa } \\
\text { Agropecuária }\end{array}$ & 41,23 & 3,08 & 5,0 \\
\hline
\end{tabular}

A Tabela 2 mostra os valores médios para os estados dos recursos $\bar{\lambda}_{n}$ após a convergência do algoritmo de simulação social, assim como o desvio padrão para a mesma variável $\delta\left(\lambda_{m}\right)$. Apenas três recursos estabilizaram com elevados níveis de acesso, a "consultoria em sustentabilidade", controlada pela Pronese; o "espaço rural", controlado pela 
Asscomprod; e a "mobilização sociopolítica" controlada pelo Sindicato. Os demais recursos estabilizaram em torno da neutralidade, mais próximo de zero, o que denota que este sistema socioterritorial mostra certa neutralidade face as iniciativas municipais e à evolução tecnológica. Os baixos valores dos desvios dos estados dos recursos sugerem que o sistema social apresenta estrutura determinística [32].

Tabela 2: Recursos (com seus identificadores Rm e rótulos das variáveis dos seus estados Statem), valores médios e os desvios para o estado (disponibilidade) de cada um considerando as simulações que convergiram para a estabilidade do sistema social.

\begin{tabular}{|c|c|c|c|c|}
\hline ID & Recurso & $\begin{array}{l}\text { Descrição do recursos e intervalo de } \\
\text { acessibilidade }\end{array}$ & $\bar{\lambda}_{n}$ & $\delta\left(\lambda_{m}\right)$ \\
\hline $\begin{array}{c}\mathrm{R} 1 \\
(\text { State1) }\end{array}$ & $\begin{array}{l}\text { Consultoria em } \\
\text { sustentabilidade }\end{array}$ & $\begin{array}{l}\text { Consultoria em políticas públicas de } \\
\text { desenvolvimento sustentável para as } \\
\text { zonas rurais. Não há nenhuma restrição } \\
\text { para acessar esse recurso, de modo que } \\
\text { a acessibilidade está no intervalo [- } \\
\text { 10,10]. }\end{array}$ & 9,72 & 0,44 \\
\hline $\begin{array}{c}\mathrm{R} 2 \\
(\text { State2) }\end{array}$ & $\begin{array}{l}\text { Assistência técnica e } \\
\text { extensão rural }\end{array}$ & $\begin{array}{l}\text { A falta de capacidade estrutural limita o } \\
\text { acesso a este recurso.Acesso no } \\
\text { intervalo }[-8,8] \text {. }\end{array}$ & 3,37 & 1,58 \\
\hline $\begin{array}{c}\mathrm{R} 3 \\
\text { (State3) }\end{array}$ & Difusão de tecnologia & Faixa de acesso é $[-10,6]$. & 5,89 & 0,19 \\
\hline $\begin{array}{c}\mathrm{R} 4 \\
(\text { State4) }\end{array}$ & Espaço rural & $\begin{array}{l}\text { O acesso pode não ser completo, mas } \\
\text { raramente é inacessível, }[-9,9] \text {. }\end{array}$ & 7,13 & 1,62 \\
\hline $\begin{array}{c}\mathrm{R} 5 \\
(\text { State5) }\end{array}$ & Recursos financeiros & O intervalo de acesso é $[-6,6]$. & 4,93 & 1,31 \\
\hline $\begin{array}{c}\text { R6 } \\
\text { (State6) }\end{array}$ & $\begin{array}{l}\text { Plano de } \\
\text { desenvolvimento } \\
\text { municipal }\end{array}$ & $\begin{array}{l}\text { O plano de desenvolvimento municipal } \\
\text { por CONDEM (Conselho Econômico } \\
\text { de Desenvolvimento Municipal) ou o } \\
\text { CMDS (Conselho Municipal para o } \\
\text { Desenvolvimento Sustentável). Pode } \\
\text { assumir situações extremas, [-10,10]. }\end{array}$ & 1,28 & 3,71 \\
\hline $\begin{array}{c}\mathrm{R} 7 \\
\text { (State7) }\end{array}$ & $\begin{array}{l}\text { Políticas públicas para o } \\
\text { desenvolvimento } \\
\text { municipal sustentável }\end{array}$ & $\begin{array}{l}\text { Este recurso pode assumir situações } \\
\text { extremas, com acesso no intervalo [- } \\
10,10]\end{array}$ & 3,16 & 3,59 \\
\hline $\begin{array}{c}\mathrm{R} 8 \\
\text { (State8) }\end{array}$ & $\begin{array}{l}\text { Mobilização } \\
\text { sociopolitica }\end{array}$ & $\begin{array}{l}\text { Entende-se mobilização sociopolítica } \\
\text { como a capacidade do sindicato dos } \\
\text { trabalhadores rurais para mobilizar } \\
\text { pessoas para um engajamento político- } \\
\text { ideológico. Intervalo de acesso é igual a } \\
{[-9,9] \text {. }}\end{array}$ & $-8,87$ & 0,21 \\
\hline $\begin{array}{c}\text { R9 } \\
\text { (State9) }\end{array}$ & $\begin{array}{l}\text { Conhecimento } \\
\text { tecnológico }\end{array}$ & $\begin{array}{l}\text { O acesso a este recurso é relativamente } \\
\text { limitado, }[-5,5] \text {. }\end{array}$ & 3,35 & 2,13 \\
\hline
\end{tabular}

A validação da modelagem e simulação foi realizada por meio de entrevistas com pesquisadores diretamente envolvidos com o TRSS e com a assessora do colegiado territorial. Os entrevistados confirmaram os resultados da simulação e fizeram algumas observações importantes acerca da governança do território, são elas: a Emdagro tem grande visibilidade mas a intensidade de sua participação no TRSS vem decrescendo, assim como sua capacidade de disponibilizar os recursos que controla; o fluxo de recursos do Banco Mundial durante o período da pesquisa projetou a Pronese, responsável pela elaboração dos projetos de financiamento e contato com os produtores da agricultura familiar, como um importante protagonista no TRSS, o que não mais se observa atualmente; há conflitos entre a política pública federal e outras políticas de territorialização; as políticas públicas de suporte financeiro aos territórios são majoritariamente 'de cima para baixo', o que fragiliza as iniciativas da base e dificulta o jogo social cooperativo. 


\subsection{Dados (saídas do sistema soclab)}

Cada simulação $S_{i}$ gera um vetor de dados $\mathbf{x}_{i}$ contendo o número de etapas necessárias $s_{i}$ para se atingir o equilíbrio do sistema social, os valores finais dos estados dos recursos $\lambda_{i m}$ e os valores da capacidade de ação $C_{i n}$ de cada ator social. Logo, cada simulação gerará um vetor de dados $\mathbf{x}_{i}=\left[s_{i}, \lambda_{i 1}, \lambda_{i 2}, \ldots, \lambda_{i m}, C_{i 1}, C_{i 2}, \ldots, C_{i n}\right]^{\mathrm{T}}, \quad$ ou $\quad \mathbf{x}_{i}=$ $[\text { step, state } 1 \text {, state } 2, \ldots, \text { statem, } \operatorname{CoA} 1, \operatorname{CoA} 2, \ldots, \operatorname{CoAn}]^{\mathrm{T}}$, onde $m$ corresponde ao número de recursos do sistema e $n$ ao número de atores sociais.

\subsection{Análise estatística}

O sistema socioterritorial é formado por atores sociais e recursos que criam, por meio das relações de controle e dependência, elos de interdependência entre as capacidades de ação dos atores sociais e os estados dos recursos, controlados pelos mesmos que, provavelmente afetam a correlação entre as variáveis estudadas. Dessa forma, visando identificar interrelações entre as variáveis de $\mathbf{x}_{i}$ e explicá-las através de um conjunto menor de variáveis estatísticas, foi utilizada a análise fatorial através do método de componentes principais [30]. Também, foi realizada a análise de agrupamentos pelos métodos hierárquico aglomerativo e k-médias. Através desses métodos, buscou-se identificar padrões de comportamento nos agregados construídos a partir do conjunto de dados estudados. O perfil de cada agrupamento foi apresentado através do gráfico to tipo boxplot.

Segundo Chapron (2012) [32], o que deve ser observado nas variáveis é a sua dispersão total e nos agregados, se houver. Segundo o autor, a estrutura social pode ser determinística quando a dispersão das variáveis relativas aos estados finais dos recursos é baixa, ou multimodal para o caso dessa dispersão ser elevada. Neste último caso significa dizer que o sistema socioterritorial converge para diferentes configurações dos estados dos recursos. Outro fator que auxilia a classificação da estrutura social é o número de etapas para a convergência, quanto maior for esse valor mais complexa será a estrutura social, ou seja, maior será o esforço do algoritmo heurístico de aprendizagem. Caso a convergência seja alcançada em poucas etapas o sistema social poderá ser classificado como simples.

\subsection{Mapas Auto-Organizáveis de Kohonen}

Os Mapas Auto-Organizáveis de Kohonen são redes neurais artificiais não-supervisionadas cuja principal função é ordenadar os dados de entrada numa grade bidimensional de neurônios por meio de um processo de quantização vetorial onde os pesos de cada neurônio são modificados de forma a se aproximar dos valores dos dados de entrada. Ao final, cada neurônio da grade estará associado a um conjunto de vetores de entrada, sendo que neurônios vizinhos na grade representam vetores de entradas próximos no espaço de atributos [22]. Neste caso a dispersão das variáveis serão avaliadas de acordo com a sua posição na grade neural.

Este trabalho utilizou o algoritmo de aprendizagem sequencial e a técnica de análise das variáveis por meio dos planos de componentes conforme exposto em Silva, Siqueira e Teixeira (2010, p. 431-432) [31]. O Plano de Componente é uma representação gráfica da rede neural SOM, por variável, onde os valores dos pesos por variável e por neurônio são interpretados segundo uma paleta de cores onde o azul intenso significa valores baixos, o amarelo intenso valores elevados, e as cores verde e ciano valores intermediários. Padrões de distribuição de cores semelhantes no mapa neural entre duas variáveis significa que as mesmas são correlacionadas.

Optou-se por uma rede bidimensional (12x8), hexagonal, função de vizinhança gaussiana com raio inicial igual a 8, 10000 ciclos de treinamento e taxa de aprendizagem inicial igual a 0,05 . Para a análise dos planos de componentes a partir de pequenas quantidades de dados $n$ ' basta definir uma rede neural com $m$ ' neurônios, $m^{\prime} \sim n$ '. Não há variação significativa na análise dos planos de componentes para redes neurais com $m$ ' $>n^{\prime}$. 


\subsection{Recursos computacionais}

As simulações sociais foram realizadas por meio do programa Soclab 2.1, as análises estatísticas foram conduzidas por meio dos programas SPSS 17 e R 2.12 (pacote stats v. 3.4.0) e o processamento dos dados na rede neural e a geração dos Planos de Componentes foram realizados por meio do programa SOM Toolbox 2.0.

\section{RESULTADOS E DISCUSSÃO}

\subsection{Análise estatística}

A análise da variável relativa ao número de etapas para a convergência mostrou que a mesma ocorre de forma rápida, 73883 etapas em média de um total de 200000 possíveis, denotando uma estrutura simples para o sistema socioterritorial. Foram avaliadas as correlações entre todas as variáveis estudadas (Tabela 3). As variáveis que apresentaram correlações significativas foram submetidas ao teste de adequação da amostra e submetidas ao método de componentes principais. De acordo com os resultados, sete variáveis apresentaram medidas de adequação individual e geral significativas (acima de 0,50) e foram selecionadas para compor os fatores representativos do conjunto de dados estudados (Tabela 4).

As variáveis selecionadas pelo teste de adequabilidade foram submetidas ao método rotacionado (Varimax). De acordo com os resultados, dois fatores explicaram cerca de $80 \%$ da variabilidade dos dados (Tabela 5). Também, observou-se que as variáveis selecionadas para compor o modelo fatorial apresentaram alta comunalidade (Tabela 6).

Tabela 3: Correlação entre as variáveis estudadas.

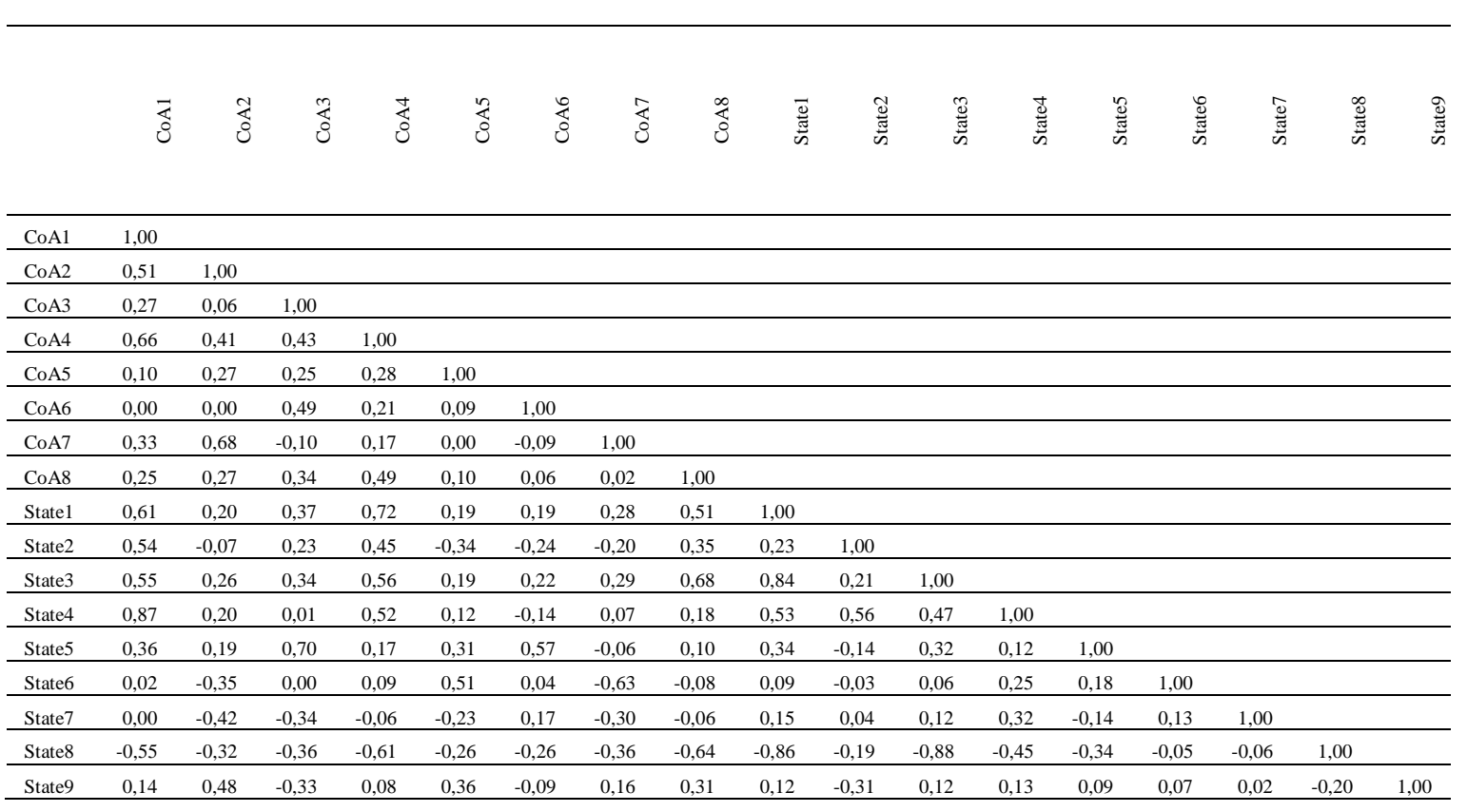


Tabela 4: Variáveis selecionadas para análise de components principais: medidas de adequação individual e geral

\begin{tabular}{cccccccc}
\hline & CoA1 & CoA8 & State1 & State2 & State3 & State4 & State8 \\
\hline CoA1 & $0,778^{\mathrm{a}}$ & 0,169 & $-0,089$ & $-0,242$ & $-0,026$ & $-0,679$ & 0,194 \\
\hline CoA8 & 0,169 & $0,688^{\mathrm{a}}$ & 0,145 & $-0,524$ & $-0,422$ & 0,203 & 0,270 \\
\hline State1 & $-0,089$ & 0,145 & $0,875^{\mathrm{a}}$ & $-0,016$ & $-0,337$ & $-0,057$ & 0,444 \\
\hline State2 & $-0,242$ & $-0,524$ & $-0,016$ & $0,639^{\mathrm{a}}$ & 0,197 & $-0,287$ & $-0,184$ \\
\hline State3 & $-0,026$ & $-0,422$ & $-0,337$ & 0,197 & $0,830^{\mathrm{a}}$ & $-0,158$ & 0,397 \\
\hline State4 & $-0,679$ & 0,203 & $-0,057$ & $-0,287$ & $-0,158$ & $0,745^{\mathrm{a}}$ & $-0,081$ \\
\hline State8 & 0,194 & 0,270 & 0,444 & $-0,184$ & 0,397 & $-0,081$ & $0,830^{\mathrm{a}}$ \\
\hline $\begin{array}{l}\text { Medida de adequação geral } \\
\text { Medida Kaiser-Meyer-Olkin de adequação da amostra (>0,50) }\end{array}$ & $\begin{array}{c}\text { Approx. Chi-quadrado } \\
\text { graus de Liberdade } \\
\text { Seste de esfericidade de Bartlett (sig }<0,05)\end{array}$ & $\begin{array}{l}0,786 \\
603,581 \\
21 \\
0,000\end{array}$ \\
\end{tabular}

Tabela 5: Número de fatores selecionados para representar o conjunto de dados estudados.

\begin{tabular}{|c|c|c|c|c|c|c|c|c|c|}
\hline \multirow[b]{2}{*}{ Componente } & \multicolumn{3}{|c|}{ Autovalores iniciais } & \multicolumn{3}{|c|}{$\begin{array}{c}\text { Extração da soma dos quadrados } \\
\text { das cargas }\end{array}$} & \multicolumn{3}{|c|}{$\begin{array}{c}\text { Rotação da soma dos quadrados } \\
\text { das cargas }\end{array}$} \\
\hline & Total & $\begin{array}{c}\% \text { de } \\
\text { variância }\end{array}$ & $\begin{array}{c}\% \\
\text { cumulativo }\end{array}$ & Total & $\begin{array}{c}\% \text { de } \\
\text { variância }\end{array}$ & $\begin{array}{c}\% \\
\text { cumulativo }\end{array}$ & Total & $\begin{array}{c}\% \text { de } \\
\text { variância }\end{array}$ & $\begin{array}{c}\% \\
\text { cumulativo }\end{array}$ \\
\hline 1 & 4,223 & 60,328 & 60,328 & 4,223 & 60,328 & 60,328 & 3,223 & 46,041 & 46,041 \\
\hline 2 & 1,386 & 19,804 & 80,132 & 1,386 & 19,804 & 80,132 & 2,386 & 34,091 & 80,132 \\
\hline 3 & 0,802 & 11,453 & 91,585 & & & & & & \\
\hline 4 & 0,227 & 3,237 & 94,822 & & & & & & \\
\hline 5 & 0,138 & 1,966 & 96,787 & & & & & & \\
\hline 6 & 0,121 & 1,727 & 98,515 & & & & & & \\
\hline 7 & 0,104 & 1,485 & 100,000 & & & & & & \\
\hline
\end{tabular}

Tabela 6: Comunalidades das variáveis selecionadas pelo método de componentes principais.

\begin{tabular}{ccc}
\hline & Inicial & Extração \\
\hline CoA1 & 1,000 & 0,867 \\
\hline CoA8 & 1,000 & 0,604 \\
\hline State1 & 1,000 & 0,828 \\
\hline State2 & 1,000 & 0,623 \\
\hline State3 & 1,000 & 0,912 \\
\hline State4 & 1,000 & 0,871 \\
\hline State8 & 1,000 & 0,905 \\
\hline
\end{tabular}

Com base na análise das cargas fatoriais, obtidas através do método rotacionado Varimax (Tabela 7), observa-se que as variáveis CoA8, State1, State3 e State8 apresentaram as maiores cargas no primeiro fator. Já no segundo fator, as variáveis CoA1, State2 e State4 apresentaram cargas mais elevadas.

Na Tabela 8 são apresentadas as correlações das variáveis selecionadas pelo método de componentes principais. A correlação entre as variáveis CoA8, State1 e State3 sugere que há forte correlação positiva entre a capacidade de ação da Embrapa e os estados dos recursos "difusão de tecnologia" (controlado pela Emdagro) e "consultoria em sustentabilidade" (controlado pela Pronese). Isso significa que quanto maior a capacidade de difusão de tecnologias da Emdagro e maior o alcance na elaboração de projetos de desenvolvimento rural sustentáveis da Pronese, maior será a capacidade de ação da Embrapa. No entanto, a relação entre Embrapa e Pronese é indireta pois não foi modelada nenhuma função de efeito entre estes dois atores sociais. Observa-se que a variável State8 se correlacionou negativamente com as demais variáveis do $1^{\circ}$ fator.

A correlação entre as variáveis CoA1, State 2 e State4 sugerem que há forte correlação positiva entre a capacidade de ação da Pronese e os estados dos recursos "assistência técnica e extensão rural" (controlado pela Emdagro) e "espaço rural" (controlado pela Asscomprod). De fato, a 
Pronese, por meio do seu recurso, atua como o elo de ligação entre a Asscomprod e os bancos, tendo a Emdagro como suporte na implementação de suas políticas públicas.

Tabela 7: Cargas fatorias das variáveis selecionadas para representar o conjunto de dados estudados.

\begin{tabular}{ccc}
\hline & \multicolumn{2}{c}{ Componente } \\
\hline & 1 & 2 \\
\hline CoA1 & 0,367 & 0,856 \\
\hline CoA8 & 0,775 & 0,065 \\
\hline State1 & 0,845 & 0,337 \\
\hline State2 & 0,051 & 0,787 \\
\hline State3 & 0,923 & 0,245 \\
\hline State4 & 0,257 & 0,897 \\
\hline State8 & $-0,924$ & $-0,227$ \\
\hline
\end{tabular}

Tabela 8: Correlação entre as variáveis selecionadas pelo método de componentes principais.

\begin{tabular}{lccccccc}
\hline & CoA8 & State1 & State3 & State8 & CoA1 & State2 & State4 \\
\hline CoA8 & 1,00 & & & & & & \\
State1 & 0,51 & 1,00 & & & & & \\
State3 & 0,68 & 0,84 & 1,00 & & & & \\
State8 & $-0,64$ & $-0,86$ & $-0,88$ & 1,00 & & & \\
CoA1 & 0,25 & 0,61 & 0,55 & $-0,55$ & 1,00 & & \\
State2 & 0,35 & 0,23 & 0,21 & $-0,19$ & 0,54 & 1,00 & \\
State4 & 0,18 & 0,53 & 0,47 & $-0,45$ & 0,87 & 0,56 & 1,00 \\
\hline
\end{tabular}

Visando identificar a dispersão intra e inter grupos no conjunto de dados estudados, as variáveis foram submetidas à técnica de análise de agrupamentos (procedimento hierárquico e não hierárquico). Com o propósito de obter uma maior separação dos agregados, os dados foram padronizados. Três simulações foram removidas porque não convergiram ou porque não apresentaram nenhuma característica que as diferenciasse das outras observações.

De acordo com a técnica de análise de agrupamentos, a solução com quatro agregados foi selecionada para representar o conjunto de dados estudado (Figura 2). Nas Tabela 9 e 10 são apresentadas as médias dos agregados para o conjunto completo de variáveis e para as variáveis selecionadas pelo método de componentes principais. Em seguida, são apresentados os dendogramas para as duas soluções de agrupamentos (Figura 2 e 3) e a distribuição dos dados nos agregados (Figuras 4 e 5).

Tabela 9: Médias das variáveis analisadas considerando a solução de quarto agrupamentos construído com o conjunto completo de variáveis.

\begin{tabular}{|c|c|c|c|c|c|c|c|c|c|c|c|c|c|c|c|c|c|c|}
\hline$\overline{8}$ & $\frac{\pi}{8}$ & $\frac{2}{8}$ & 荙 & $\frac{1}{8}$ & d̊ & త্ & ষ্ & 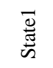 & $\begin{array}{l}\tilde{\Xi} \\
\text { 荧 }\end{array}$ & $\frac{\hat{2}}{\tilde{w}}$ & 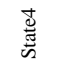 & 总 & 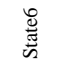 & 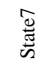 & 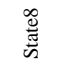 & 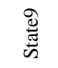 & 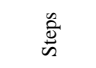 & z \\
\hline 54,41 & 26,30 & 37,59 & 56,99 & 19,15 & 31,77 & 21,16 & 41,69 & 9,81 & 3,90 & 5,83 & 7,80 & 5,31 & $-0,66$ & 1,49 & $-8,94$ & 4,01 & 60222,55 & 42 \\
\hline 39,49 & 19,98 & 32,49 & 51,10 & 21,32 & 33,14 & 19,20 & 42,23 & 9,26 & 1,20 & 5,86 & 4,74 & 4,40 & 0,22 & 2,16 & $-8,88$ & 4,72 & 95536,50 & 20 \\
\hline 50,33 & 16,77 & 32,76 & 55,45 & 23,01 & 31,33 & 8,51 & 40,19 & 9,89 & 3,39 & 5,95 & 8,30 & 5,05 & 6,20 & 6,57 & $-8,80$ & 3,89 & 71939,25 & 24 \\
\hline 45,73 & 9,38 & 45,78 & 55,06 & 13,06 & 36,76 & 11,45 & 39,26 & 9,78 & 4,81 & 5,99 & 6,19 & 5,17 & 0,89 & 3,31 & $-8,75$ & $-3,01$ & 70511,82 & 11 \\
\hline
\end{tabular}

Tabela 10: Médias das variáveis analisadas considerando a solução de quarto agrupamentos construído com o conjunto selecionado de variáveis.

\begin{tabular}{ccccccccc}
\hline CoA1 & CoA8 & State1 & State2 & State3 & State4 & State8 & Steps & N \\
\hline 52,7 & 38,8 & 9,87 & 2,89 & 5,85 & 8,02 & $-8,91$ & 61749 & 42 \\
\hline 43,6 & 45,4 & 8,98 & 3,21 & 5,9 & 5,35 & $-8,81$ & 87138 & 18 \\
\hline 38,3 & 40,3 & 9,83 & 0,85 & 5,83 & 4,43 & $-8,95$ & 88170 & 15 \\
\hline 55,2 & 42,8 & 9,94 & 5,92 & 5,97 & 8,64 & $-8,8$ & 66261 & 22 \\
\hline
\end{tabular}




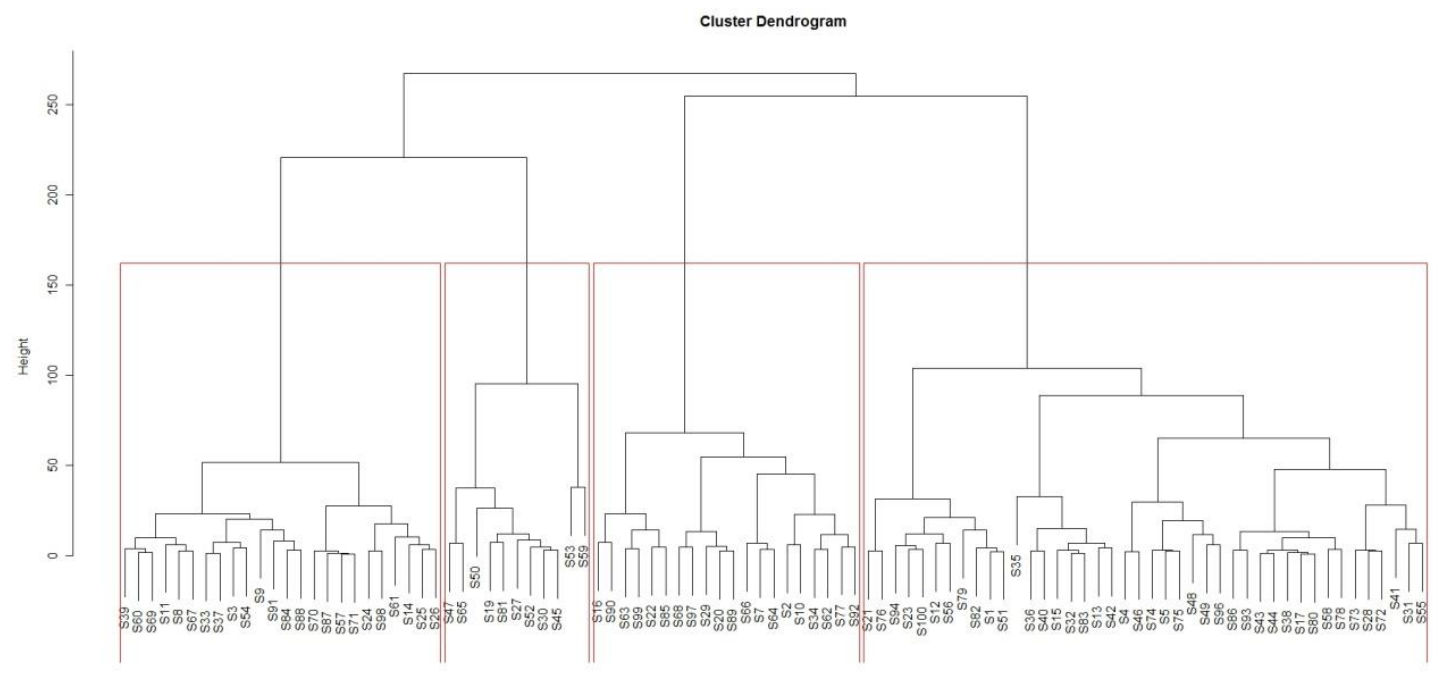

distancia
ndoust(': vards)

Figura 2: Dendograma construído para a solução de quarto agrupamentos (conjunto completo de variáveis)

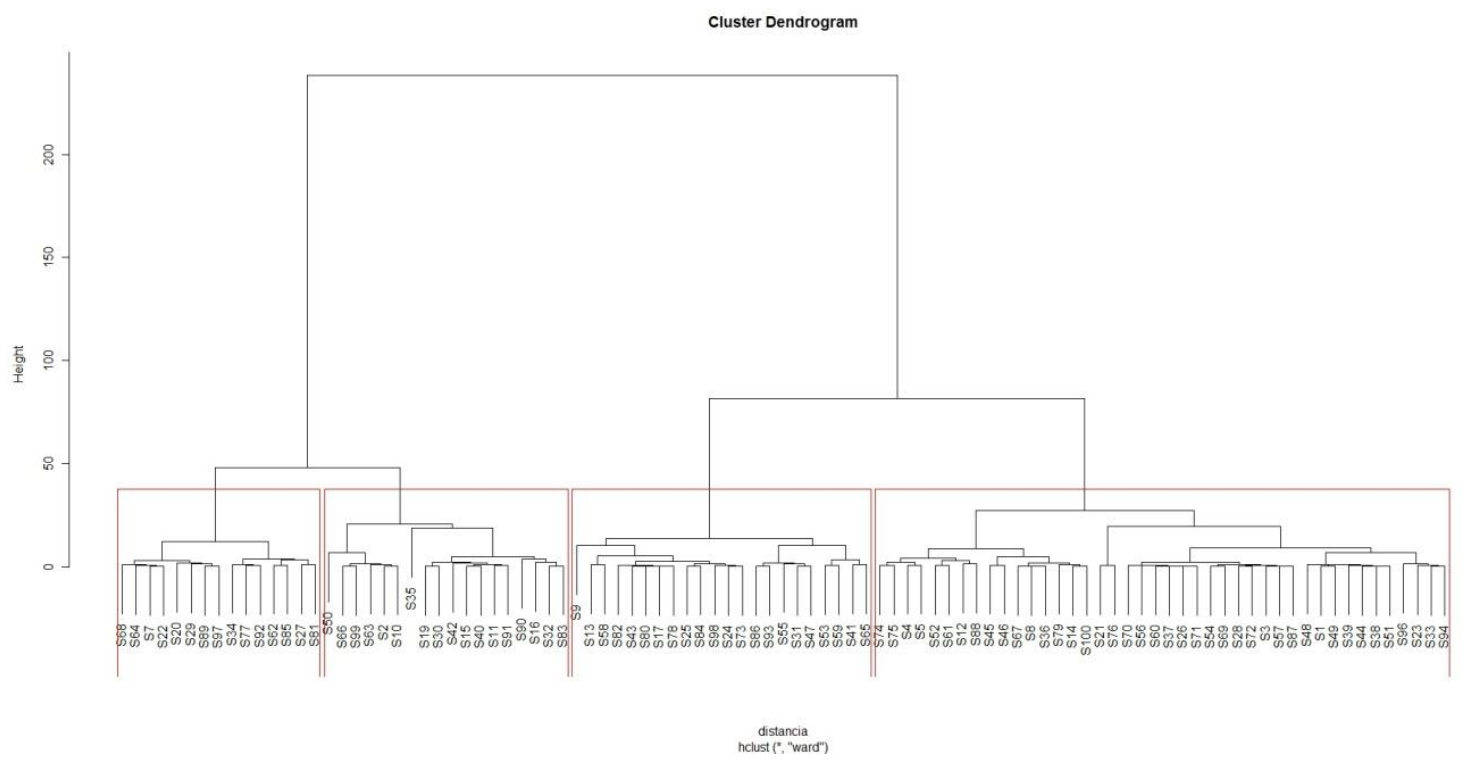

Figura 3: Dendograma construído para a solução de quarto agrupamentos (variáveis selecionadas pelo método de componentes principais) 


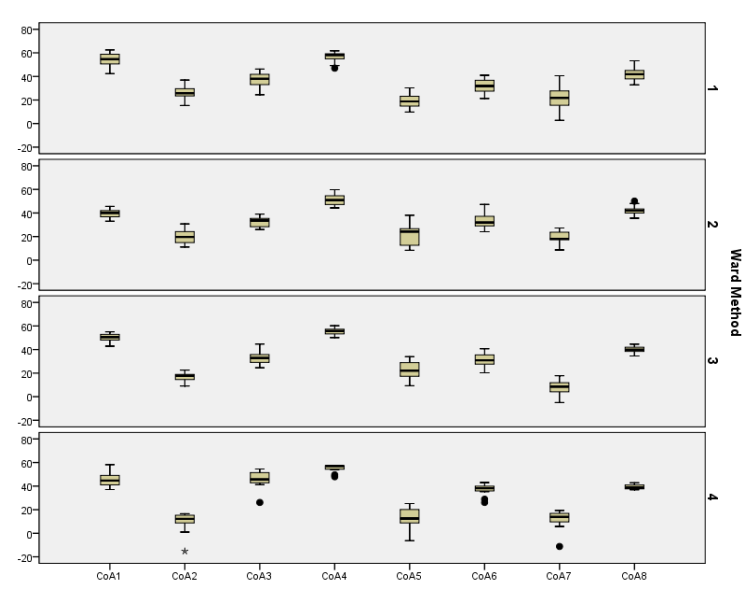

(a)

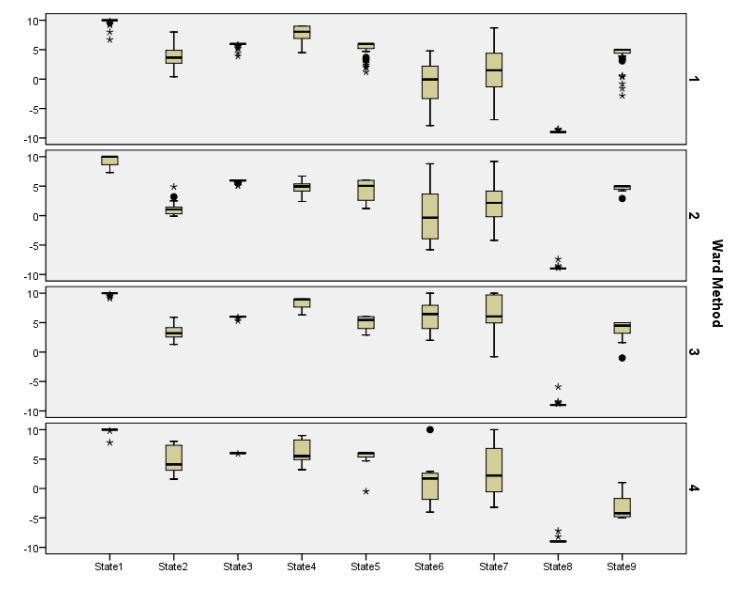

(b)

Figura 4: Distribuição dos dados nos agrupamentos construídos com o conjunto completo das variáveis a) atores sociais e b) recursos.

A análise de agrupamentos e da distribuição dos dados nos agregados mostraram que há pouca variação intergrupos tanto para as variáveis relativas à capacidade de ação dos atores sociais $(\mathrm{CoA} n)$ como para as variáveis relativas aos estados dos recursos compartilhados (Statem). Os resultados denotam, portanto, que o sistema socioterritorial em questão é estável e apresenta pouca variação no espaço das estratégias do jogo social, ou seja, ele é determinístico.

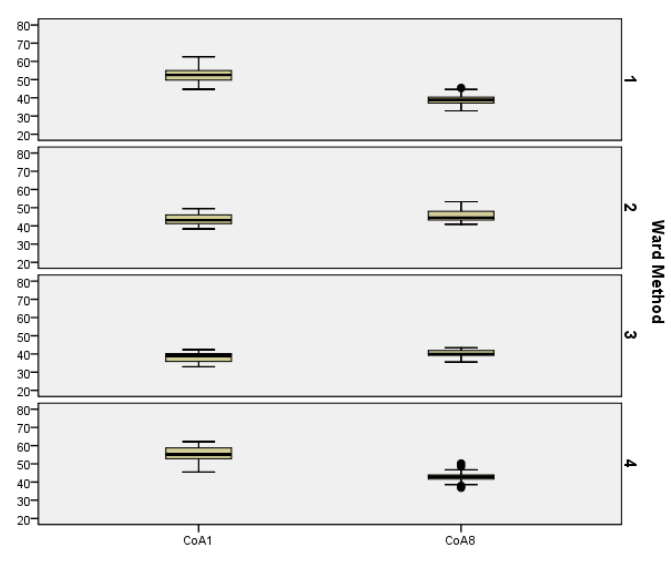

(a)

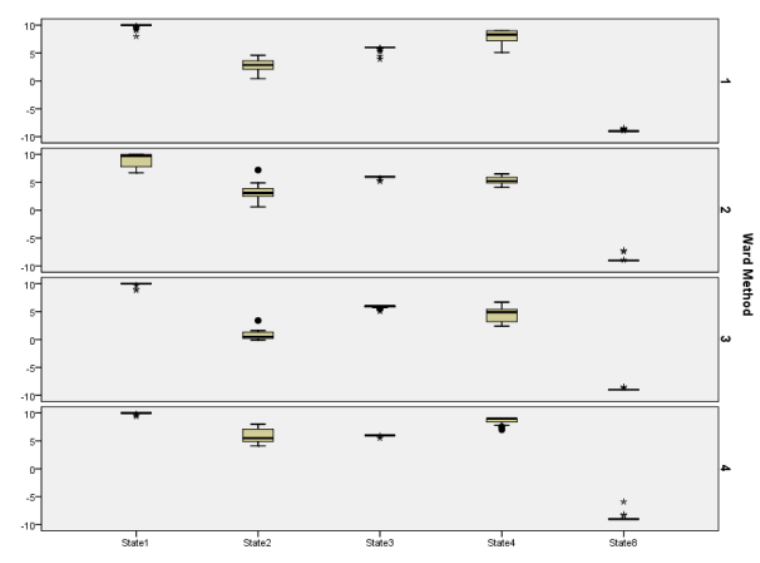

(b)

Figura 5: Distribuição dos dados nos agrupamentos de variáveis selecionadas pelo método de componentes principais: a) atores sociais e b) recursos.

\subsection{Mapas Auto-Organizáveis de Kohonen}

A Figura 6 mostra a configuração final da rede neural 12x8, grade hexagonal, após o processo de aprendizagem sequencial não-supervisionada. Cada simulação, representada por seu rótulo, está associada a um único neurônio, representado graficamente por um hexágono. As simulações que não convergiram, S18 e S95, encontram-se no topo da rede neural. Mais de $70 \%$ das 
simulações encontram-se na metade inferior do mapa neural. A distribuição das simulações na rede SOM mostra que, apesar da concentração de rótulos na parte inferior do mapa, houve dispersão das situações possíveis de estabilidade no jogo social.

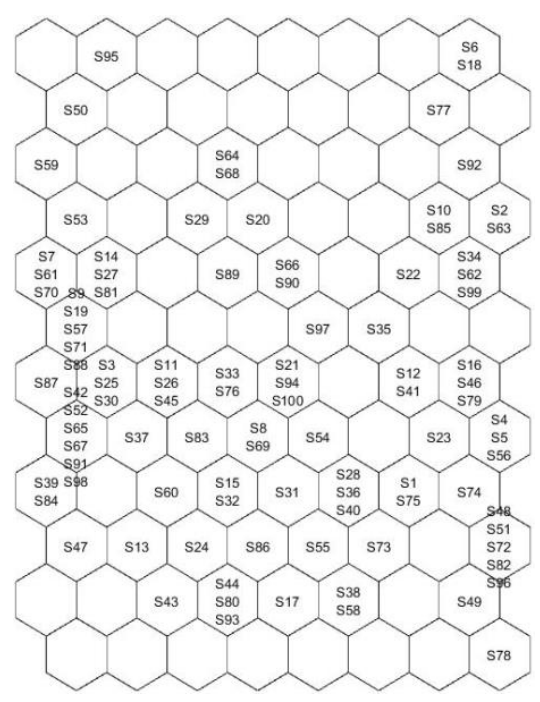

Figura 6: Configuração final do mapa neural $12 x 8$ após o processo de aprendizagem não-supervisionada. Cada neurônio pode estar associado a uma ou mais simulações, representadas por seus rótulos.

As linhas tracejadas presentes nos planos de componentes dividem o mapa neural em oito áreas de acordo com o padrão de distribuição de cada variável (Figura 7). Por exemplo, a capacidade de ação do ator social Pronese (Figura8a) apresenta valores abaixo da média na parte superior do mapa neural e valores superiores à média na parte inferior, tendo como região limítrofe a região central do mapa. Neste caso, a linha tracejada será horizontal cortando o mapa neural ao meio. De maneira análoga, procede-se a interpretação dos planos de componentes, gerando ao final, os quatro cortes, separando as simulações em oito grupos, conforme mostrados na Figura 7.

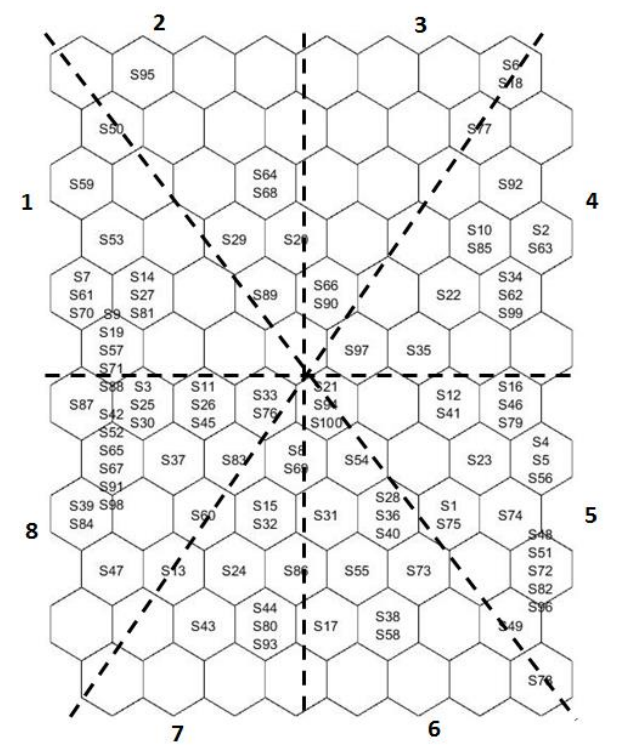

Figura 7: Divisão do mapa neural a partir da interpretação dos planos de componentes. 
A Figura 8 mostra os oito planos de componentes relativos à capacidade de ação de cada ator social após as simulações. Observa-se que, pelo padrão de cores, há indícios de correlação positiva entre as capacidades de ação dos atores sociais Pronese (CoA1), Banco (CoA4), ConselhosMun (CoA5) e Embrapa (CoA8); e entre as capacidades de ação dos atores Asscomprod (CoA3) e Prefeitura (CoA6). A Emdagro (CoA2) e o Sindicado (CoA7) apresentaram padrões distintos para a variável "Capacidade de ação".

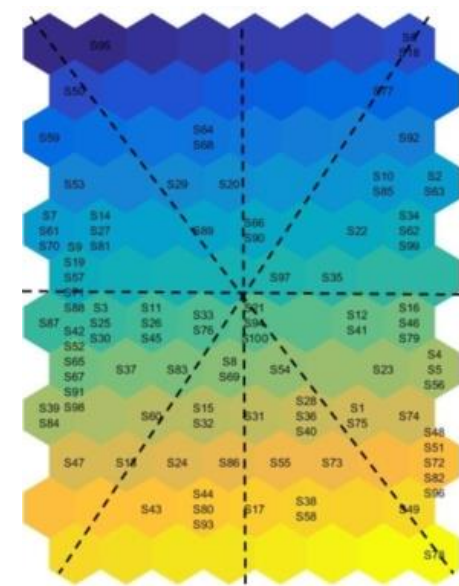

(a) CoA1 - Pronese

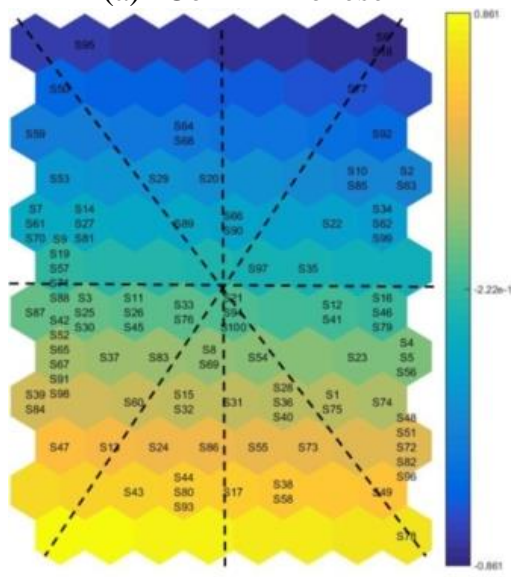

(d) $\mathrm{CoA} 4$ - Banco

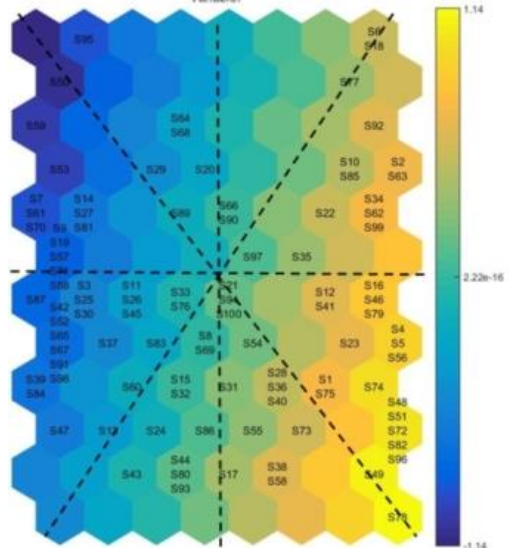

(g) CoA7 - Sindicato

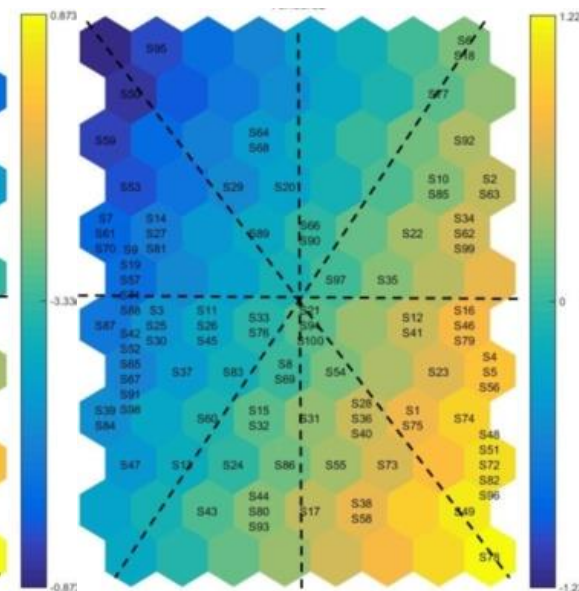

(b) $\mathrm{CoA} 2$ - Emdagro

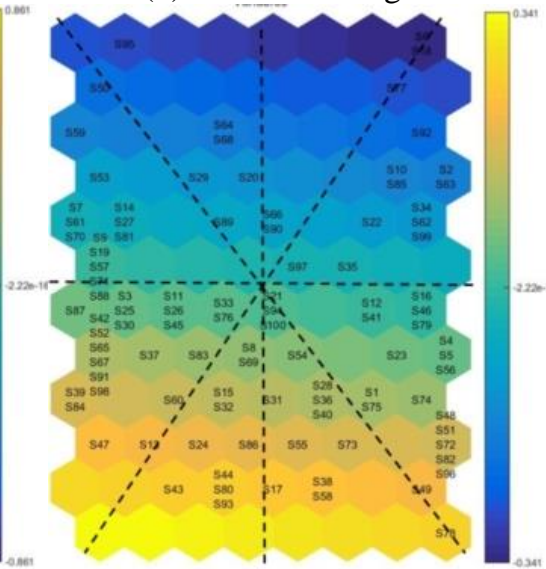

(e) CoA5 - ConselhosMun

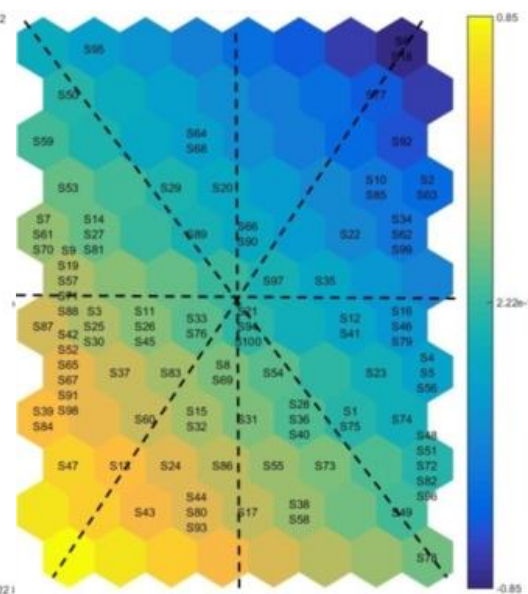

(c) CoA3 - Asscomprod

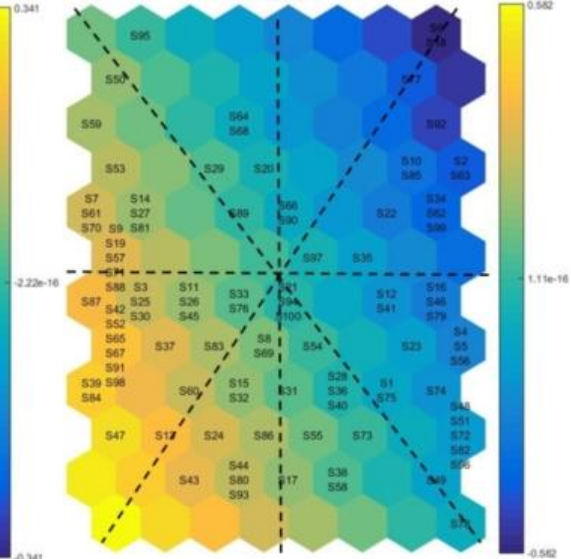

(f) CoA6 - Prefeitura

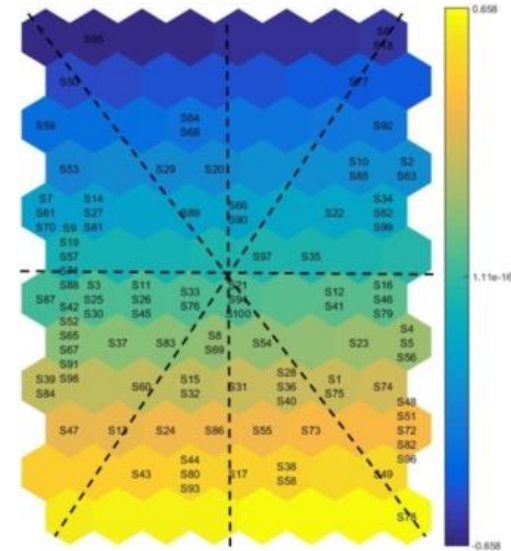

(h) CoA8 - Embrapa

Figura 8: Planos de componentes para as Capacidades de ação dos oito atores sociais. 
A Figura 9 mostra os planos de componentes para a variável "Estado dos recursos" compartilhados pelos atores sociais. De acordo com o padrão apresentado pelos planos de componentes pode-se concluir que há também indícios de correlação positiva entre as variáveis dos estados dos recursos State1, State3 e State4; os recursos State2 e State5 e entre os recursos State6 e State7. Os recursos State8 e State9 apresentaram padrões distintos dos demais. De forma análoga pode-se verificar as correlações entre as variáveis capacidade de ação e estados dos recursos. De maneira geral, as correlações visuais pelos planos de componentes (Figuras 8-9) estão compatíveis com os resultados das Tabela 3 e 7.

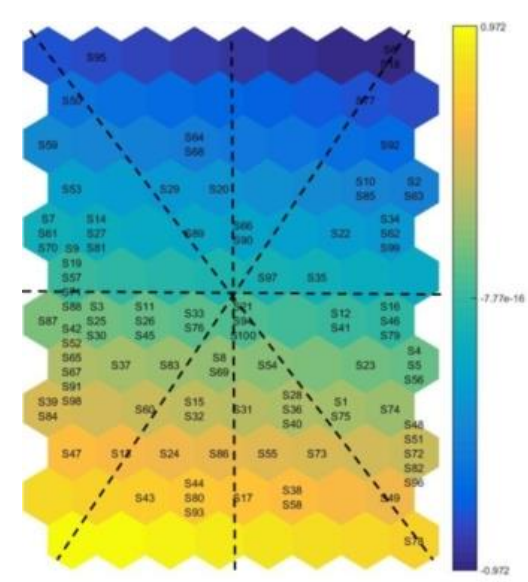

(a) State1 - consultoria em sustentabilidade

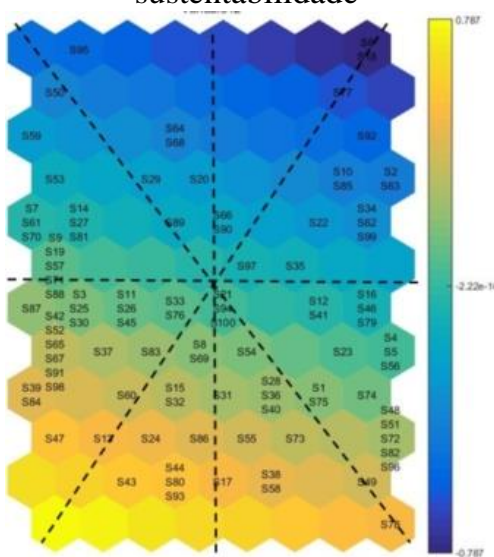

(d) State4 - espaço rural

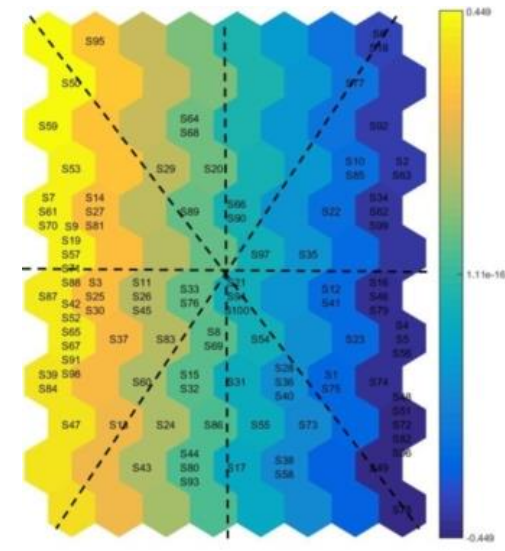

(g) State7 - políticas públicas para o desenvolvimento municipal sustentável

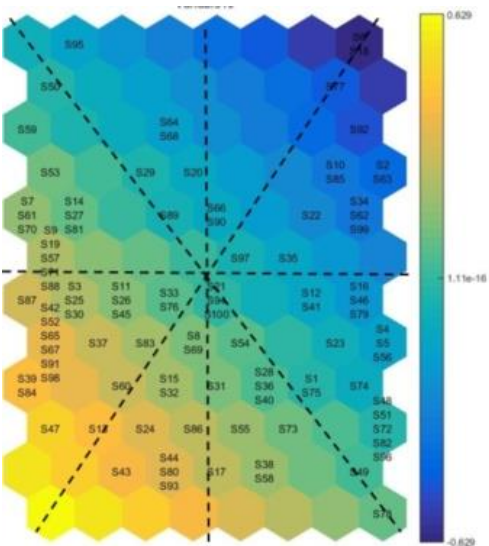

(b) State2 - assistência técnica e extensão rural

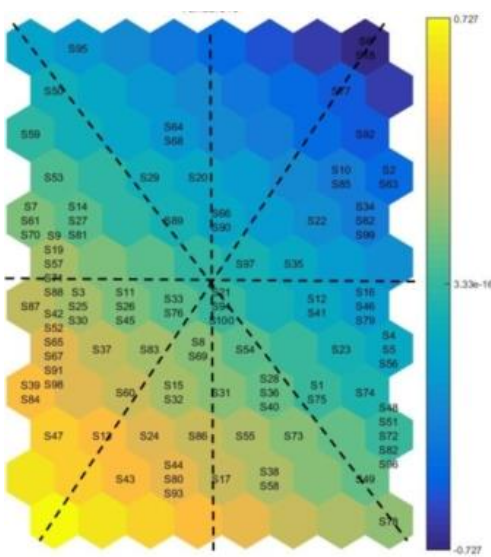

(e) State5 - recursos financeiros

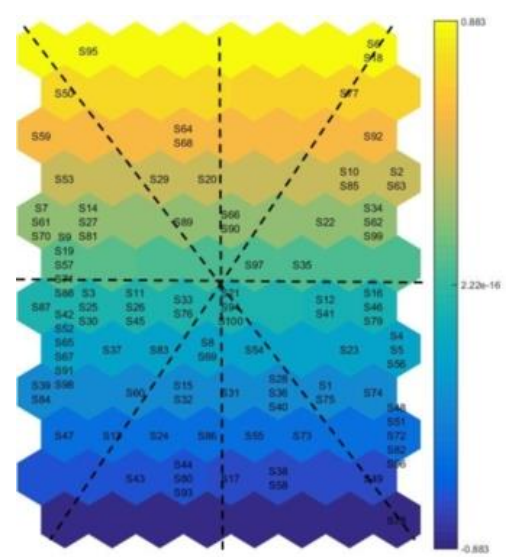

(h) State8 - mobilização sociopolítica

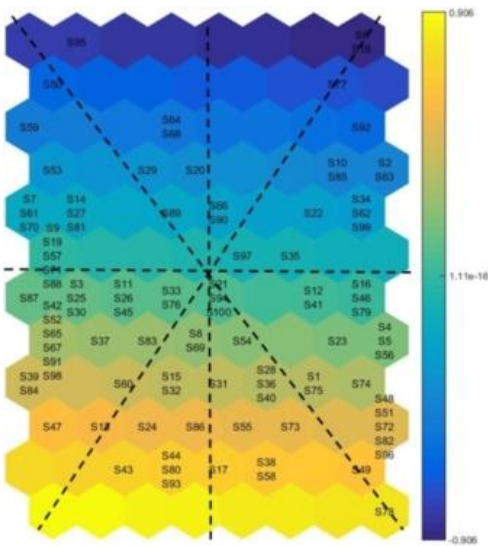

(c) State3 - difusão de tecnologia

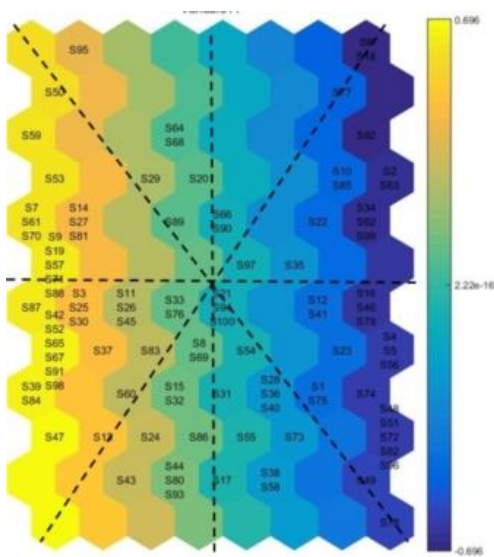

(f) State6 - plano de

desenvolvimento municipal

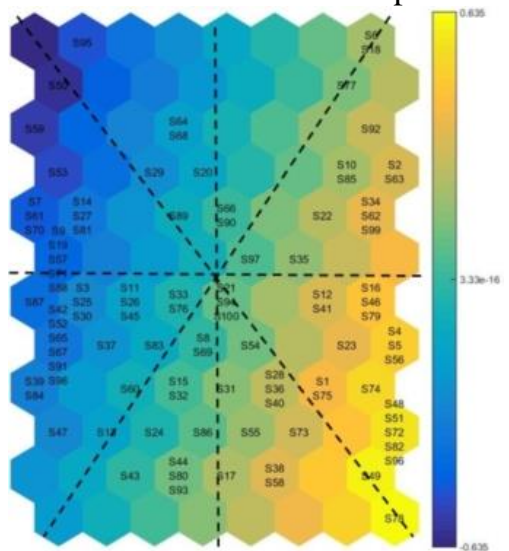

(i) State9 - conhecimento tecnológico

Figura 9: Planos de componentes para os estados dos nove recursos compartilhados pelos atores sociais. 
A observação dos oito grupos formados pela partição do mapa neural possibilita a caracterização das diferentes situações possíveis onde o sistema socioterritorial em questão encontra a sua estabilidade. Na região 8 da Figura 8 tem-se que as simulações se estabilizam quando a Pronese, a Asscomprod, o Banco, o ConselhosMun, a Prefeitura e a Embrapa estão com capacidade de ação com valores elevados, sendo que a Emdagro e o Sindicato apresentam nessa mesma situação capacidades de ação com valores baixos.

Ainda considerando a região 8 da Figura 9, observa-se que o nível de acesso aos recursos apresentam valores altos para consultoria em sustentabilidade (State1), asssitência técnica e extensão rural (State2), difusão de tecnologia (State3), espaço rural (State4), recursos financeiros (State5), plano de desenvolvimento municipal (State6) e políticas públicas para o desenvolvimento municipal sustentável (State7). Os estados dos recursos mobilização política (State8) e conhecimento tecnológico (State9) apresentaram valores baixos para essas simulações.

Quando se observa a região 5 do mapa neural rotulado da Figura 8, tem-se que as simulações convergiram quando as capacidades de ação da Pronese, da Emdagro, do Banco, do ConselhosMun, do Sindicado e da Embrapa atingiram valores altos; enquanto que as capacidades de ação de Asscomprod, da Prefeitura ficaram com valores baixos. Para estes atores o acesso aos recursos ficou restrito (cor azul nos planos de components) para os seguintes casos: assistência técnica e extensão rural, plano de desenvolvimento municipal, políticas públicas para o desenvolvimento municipal sustentável e mobilização política.

Em geral, pode-se afirmar que para a maioria dos casos onde o sistema socioterritorial convergiu, a Pronese, o Banco, o ConselhosMun e a Embrapa sempre apresentaram capacidades de ação com valores altos, cor amarela nos planos de componentes. Também verificou-se que os recursos consultoria em sustentabilidade e difusão de tecnologia convergiram para a plena acessibilidade.

\section{CONCLUSÃO}

Os resultados do trabalho permitiram concluir que o sistema socioterritorial "Território Rural Sul Sergipano" apresenta estrutura simples e determinística, ou seja, se estabiliza com poucas etapas do algoritmo heurístico de simulação social e apresenta pouca variação dos valores dos estados dos recursos.

A análise dos resultados das simulações via análise de componentes principais e rede neural artificial Mapa Auto-Organizável de Kohonen mostrou que há correlações entre, pelo menos, dois grupos de variáveis. No primeiro destacam-se as relações de dependência entre a Embrapa e os recursos consultoria em sustentabilidade, controlado pela Pronese, e difusão de tecnologia, controlado pela Emdagro. No segundo, destacam-se as relações de dependência entre a Pronese e os recursos assistência técnica e extensão rural, controlado pela Emdagro, e espaço rural, controlado pela Asscomprod.

A análise estatística de agrupamentos em conjunto com os gráficos boxplots mostraram que não há variação significativa entre os quatro grupos gerados, sendo que o sistema permanece com estrutura determinística e simples em todos os grupos. A análise da projeção dos dados por meio do mapa neural em duas dimensões confirmou as correlações estatísticas e complementou a análise de agrupamentos via método aglomerativo hierárquico, mostrando que é possível caracterizar as diferenças sutis entre as distintas situações de estabilidade do sistema socioterritorial.

\section{REFERÊNCIAS BIBLIOGRÁFICAS}

1. Cioffi-Revilla C. Introduction to computational social science: Principles and Applications. Berlin: Springer-Verlag; 2014.

2. Gilbert N, Troitzsch K G. Simulation for the social scientist. Second Edition. Berkshire : Open University Press; 2005.

3. Lazer D et al. Computational social science. Science; 2009; 323:721-724.

4. Conte R et al. Manifesto de ciência social computacional. Mediações; 2013; 18(1): 20-54, , doi: 10.5433/2176-6665.2013v18n1p20. 
5. Schelling T C. Models of segregation. American Economic Review; 1969; 59(2): 488-493.

6. Joseph K, Carley KM, Hong JI. Check-ins in "Blau space": applying Blau's macrosociological theory to foursquare check-ins from New York City. ACM Transactions on Intelligent Systems and Technology; $2013 \mathrm{~V}(\mathrm{~N})$ :A.

7. Silva LS, Marietto MGB, Ribeiro CHC. A mutli-agent model for the micro-to-macro linking derived from a computational view of the social systems theory by Luhmann. In: Luis Antunes, Mario Paolucci, Emma Norling. (Org.). LNCS; 2008; 5003:52-68.

8. Dittrich P, Kron T, Banzhaf W. On the scalability of social order: modeling the problem of double and multi contingence following Luhmann. Journal of Artificial Societies and Social Simulation; 2003; 1(1).

9. Luhmann N. Social Systems. Stanford : Stanford University Press; 1995.

10. Sibertin-Blanc C., Roggero P, Adreit F, Baldet B, Chapron P, El Gemayel J, Maillard M, Sandri S. Soclab: a framework for the modelling, simulation and analysis of power in social organizations. Journal of Artificial Societies and Social Simulation; 2013; 16(4).

11. Crozier M, Friedberd E. L'acteur et le système. Paris: Seuil; 1977.

12. Friedberg E. Le pouvoir et la règle : dynamiques de l'action organisée. Paris: Seuil; 1993.

13. Ministério do Desenvolvimento Agrário (MDA). Referências para uma estratégia de desenvolvimento rural sustentável no Brasil. Brasília, DF : SDT; 2005a. Série Documentos $\mathrm{n}^{\circ} 1$.

14. Ministério do Desenvolvimento Agrário (MDA). Referências para a gestão social de territórios rurais. Brasília, DF : SDT; 2005b. Série Documentos no 3.

15. Silva MASd, Medeiros SdS, Manos MGL, Siqueira ERd. Modelagem social computacional como instrumento de análise de sistemas sociais territoriais complexos: o caso do Território Sul Sergipano, Brasil. Campo - Território; 2014; 9:55-85.

16. Silva MASd. Modeling and simulation of a socioterritorial system: an exploratory analysis of the Southern Rural Territory of Sergipe, Brazil. In: Anais ... Dimuro, GP et al. (Org.). Proceedings of the 4th Brazilian Workshop on Social Simulation; 2014 Nov 4-7, São Paulo, SP.

17. Moine A. Le territoire : comment observer un système complexe. Paris: L'Harmattan; 2007.

18. Moine A. Le territoire comme un système complexe : un concept opératoire pour l'aménagement et la géographie. L'Éspace Géographique; 2006; 2:115-132.

19. Silva MASd, Sibertin-Blanc C, Gaudou B. Modélisation des processus sociaux pour le développement rural durable : le territoire comme système complexe d'acteurs. In: Anais ... Colóquio Nacional Ecologisation des politiques et des pratiques agricoles; 2011, L'Isle sur la Sorgue, France. Avignon: INRA PACA, 2011.

20. Furtado BA, Sakowski PAM, Tóvoli MH (Org.). Modelagem de sistemas complexos para políticas públicas. 1ed. Brasília: Instituto de Pesquisa Econômica Aplicada; 2015. Capítulo 17, O território como um sistema social complex; p. 403-436.

21. Villa-Vialaneix N, Sibertin-Blanc C, Roggero P. Statistical exploratory analysis of agent-based simulations in a social context. CS-BIGS; 2014; 5(2):132-149.

22. Kohonen T. Self-organizing maps. Berlin: Springer; 2001.

23. Ultsch A. Knowledge extraction from self-organizing neural networks. In: Opitz O, Lausen B, Klar R. (Org.). Information and Classification. Berlin: Springer; 1993.

24. Vesanto J. SOM based data visualization methods. Intelligent Data Analysis; 1999; 3(2):111-126.

25. Vesanto J, Alhoniemi E. Clustering of the Self-Organizing Map. IEEE Transactions on Neural Networks; 2000; 11(3): 586-600.

26. Siqueira ERd, Silva MASd, Aragão, AG. O território rural centro-sul de Sergipe, 1. ed. Aracaju: Embrapa Tabuleiros Costeiros; 2010.

27. Prado HA; Luiz AJB, Chaib Filho H (Org.). Computational methods for agricultural research: advances and applications. 1st ed. Hershley: Information Science Reference; 2011. Chapter 7, Using selforganizing maps for rural territorial typology; p. 107-126, doi: 10.4018/978-1-61692-871-1.ch007.

28. El Gemayel J. Un modèle par apprentissage de la rationalité des acteurs sociaux[dissertation]. Toulouse (France): Université de Toulouse 1 Capitole; 2013.

29. Simon H. A behavioral model of rational choice. Quaterly Journal of Economics; 1955; 69:99-118.

30. Hair JF, Anderson RE, Tathan RL, Black WC. Análise multivariada de dados. 6. ed. Porto Alegre: Bookman; 2009.

31. Silva MASd, Siqueira ERd, Teixeira OA. Abordagem conexionista para análise espacial exploratória de dados socioeconômicos de territórios rurais. Revista de Economia e Sociologia Rural; 2010; 48:429446, doi: 10.1590/S0103-20032010000200008.

32. Chapron P. Modélisation et analyse des organisations sociales : propriétés structurelles, régulation des comportements et évolution [dissertation]. Toulose (France): Université de Toulouse 1 Capitole; 2012.

33. Ministério do Desenvolvimento Agrário (MDA). Sistema de Informação Territorial - SIT. Disponível em: sit.mda.gov.br. Acesso em: 01 de dezembro de 2015. 